\title{
Inhibition of PI3 kinases enhances the sensitivity of non-small cell lung cancer cells to ionizing radiation
}

\author{
TAO ZHANG ${ }^{1 *}$, GUANG-BIN CUI $^{2 *}$, JIAN ZHANG $^{3 *}$, FENG ZHANG $^{4}$, \\ YONG-AN ZHOU ${ }^{1}$, TAO JIANG ${ }^{1}$ and XIAO-FEI LI ${ }^{1}$
}

\begin{abstract}
Departments of ${ }^{1}$ Thoracic Surgery, ${ }^{2}$ Radiology, Tangdu Hospital, The Fourth Military Medical University, 1 Xinsi Road, Xi'an 710038; ${ }^{3}$ Department of Respiratory Medicine, Xijing Hospital; ${ }^{4}$ Department of Pharmacology,

The Fourth Military Medical University, 17 Changlexi Road, Xi'an 710032, P.R. China
\end{abstract}

Received July 20, 2010; Accepted August 26, 2010

DOI: $10.3892 /$ or_00001034

\begin{abstract}
Non-small cell lung cancer (NSCLC) cells are relatively resistant to ionizing radiation (IR). The phosphatidylinositol 3 (PI3) kinases are members of a family of lipid kinases that mediate cellular functions, including cell growth, proliferation and DNA repair, which may contribute to radioresistance. We studied whether inhibition of PI3 kinases could increase the response of NSCLC cells to $\gamma$ irradiation. The results showed that pretreatment of PI3 kinase inhibitor wortmannin dose-dependently radiosensitized NSCLC A549 and H1650 cells by inhibiting colony formation, which was due to enhanced G2/M arrest and apoptosis by wortmannin. The accelerated apoptosis was accompanied by increased loss of mitochondrial membrane potential (MMP) and cytochrome c release to the cytoplasm. In addition, wortmannin pretreatment significantly increased caspase-3 activation, which was associated with the repression of $\mathrm{X}$-linked inhibitor of apoptosis protein (XIAP). The radiosensitizing effect of wortmannin was correlated with the inhibition of phosphorylated PKB/Akt level. Furthermore, wortmannin down-regulated the expression of DNA-dependent protein kinase catalytic subunit (DNA-PKcs) which is involved in DNA double stand break (DSB) repair, as a result, leading to the inhibition of DSBs rejoining, as indicated by increased level of $\gamma-\mathrm{H} 2 \mathrm{AX}$ at $24 \mathrm{~h}$ after IR. Taken together, our results
\end{abstract}

Correspondence to: Dr Xiao-Fei Li, Department of Thoracic Surgery, Tangdu Hospital, The Fourth Military Medical University, 1 Xinsi Road, Xi'an 710038, P.R. China

E-mail: 1xfchest@yahoo.cn

*Contributed equally

Abbreviations: NSCLC, non-small-cell lung cancer; IR, ionizing radiation; MMP, mitochondrial membrane potential; DNA-PK, DNA-dependent protein kinase; DNA-PKcs, DNA-PK catalytic subunit; XIAP, X-linked inhibitor of apoptosis protein

Key words: wortmannin, PI3K, DNA-PKcs, radiosensitivity, cell cycle, apoptosis demonstrate that wortmannin acts as a powerful radiosensitizer in NSCLC cells by inhibiting PI3K/Akt survival signaling and DNA repair protein DNA-PKcs, suggesting that PI3 kinase inhibitors may represent a novel strategy for overcoming resistance to IR-induced apoptosis in NSCLC cells.

\section{Introduction}

Lung cancer is the leading cause of cancer mortality in the world. Radiotherapy by gamma-radiation plays a major role in the local treatment of NSCLC patients by inducing DNA damage, triggering cell cycle arrest and apoptosis $(1,2)$. However, in clinical treatment, most NSCLC patients respond poorly to conventional radiotherapy because of the emergence of resistance for reasons including defects in the apoptotic machinery (3) and overexpression of genes related to cell survival $(4,5)$. Hence there is an urgent need to develop novel strategies to overcome the resistance and improve outcome of NSCLC treatment.

The phosphoinositide-3-kinase (PI3K) pathway is frequently up-regulated in human tumors (6). Elevated levels of phosphorylated PKB/Akt, the major downstream effector of PI3K, can protect cells from undergoing apoptosis by down-regulation of the pro-apoptotic Bcl-2 family and upregulation of the anti-apoptotic c-FLIP, IAPs and Bcl-2 family proteins (7), leading to increased cell survival. DNAdependent protein kinase (DNA-PK), another member of PI3 kinase family, is a nuclear serine/threonine protein kinase essential for DNA repair as well as sensing and transmitting a damage signal to downstream targets, leading to cell cycle arrest and DNA repair, thus contributing to drug resistance $(8,9)$.

Therefore, inhibition of PI3 kinases by pharmacological approach may improve the response of cancer cells to radiotherapy. Wortmannin is a widely used inhibitor of PI3 kinases (10). Wortmannin has been reported to have radiosensitization effects in RT112 bladder tumor cells (11) and BT-474 cells breast cancer cells (12) in vitro, and $\mathrm{C} 3 \mathrm{H} / \mathrm{HeJ}$ hepatocarcinoma (13) in vivo. For NSCLC cells, Sak et al (14) reported that the inhibition of DNA-dependent protein kinase activity with antisense-oligodeoxynucleotide (AsODN) or wortmannin led to marked inhibition of DNA double strand breaks (DSBs) rejoining and radiosensitization of 
NSCLC cell lines. However, the mechanisms of wortmannin on improving the radiosensitivity of NSCLC cells need to be further clarified.

In the current study, we investigated the effects of wortmannin on the response to $\gamma$-irradiation in NSCLC cells in vitro. We demonstrate that wortmannin acts as a powerful radiosensitizer in NSCLC cells in vitro by enhancing G2/M arrest and promoting apoptosis. The enhanced apoptosis was accompanied by mitochondrial injury, caspase- 3 activation and decreased DSBs repair. The radiosensitizing effect by wortmannin was correlated with its inhibition of Akt phosphorylation and the DNA repair protein DNA-PKcs. Based on these findings, we conclude that combining PI3K inhibitors and $\gamma$-irradiation may present promising strategy for clinical treatment of human NSCLC.

\section{Materials and methods}

Cell culture and treatments. NSCLC cells A549 and H1650 were grown in Dulbecco's modified Eagle's medium (DMEM, Gibco, USA) supplemented with $10 \%$ fetal bovine serum, $10 \mathrm{mg} / \mathrm{ml}$ antibiotics (penicillin and streptomycin) and $2 \mathrm{mmol} / 1 \mathrm{~L}$-glutamine at $37^{\circ} \mathrm{C}$ under $5 \% \mathrm{CO}_{2}$ and saturated moisture. Wortmannin (Sigma, St. Louis, MO, USA) was dissolved in dimethyl sulfoxide (DMSO, Sigma), final concentrations of 1,5 and $20 \mu \mathrm{M}$ were used to treat the cells and proper amount of DMSO was used as vehicle control.

Clonogenic assay. Cells were divided into the following groups: control (cells were treated with DMSO as vehicle control), WM+IR (cells were treated with 1,5 or $20 \mu \mathrm{M}$ wortmannin for $1 \mathrm{~h}$ followed by IR $5 \mathrm{~Gy}$ ), IR (cells were treated with DMSO followed by IR 5 Gy), WM (cells were treated with wortmannin $20 \mu \mathrm{M}$ ). Following different treatments, cells were incubated for $24 \mathrm{~h}$. Thereafter, cells were trypsinized and seeded in triplicate in $60-\mathrm{mm}$ dishes (500 cells per dish) and incubated for 14 days to allow for colony growth. Colonies of $>50$ cells were counted manually using a microscope.

Cell cycle analysis. At the time of harvesting, cells were digested with $0.25 \%$ trypsin (Gibco) and re-suspended in phosphate-buffered saline (PBS), fixed in $70 \%$ ethanol at $4^{\circ} \mathrm{C}$ overnight. When analyzing, cells were washed with PBS and treated with $20 \mu \mathrm{g} / \mathrm{ml}$ ribonuclease A (RNase A, Sigma) at $37^{\circ} \mathrm{C}$ for $30 \mathrm{~min}$. Cells were then stained with $50 \mu \mathrm{g} / \mathrm{ml}$ propidium iodide (PI, Sigma) for $30 \mathrm{~min}$ in the dark. DNA content was analyzed by flow cytometry with FACScan (Becton-Dickinson, Mountain View, CA, USA) using the CellQuest program (Becton-Dickinson). Cell cycle distribution was analyzed by WinMDI software.

Annexin V-FITC and PI staining. Cells were digested with trypsin and cell pellets were re-suspended in $100 \mu 1$ binding buffer [10 mM HEPES (N-2-hydroxyethylpiperazine-N-2ethanesulfonic acid), $140 \mathrm{mM} \mathrm{NaCl}$ and $2.5 \mathrm{mM} \mathrm{CaCl}_{2}$, pH 7.4]. Cells were then stained with $5 \mu 1$ Annexin V-FITC (BD Pharmingen, USA) and $5 \mu \mathrm{l}$ propidium iodide (BD Pharmingen) staining solution in the dark at room temperature (RT) for $15 \mathrm{~min}$. The cell samples were analyzed by flow cytometry on a FACScan station with CellQuest software using the FL1 and FL2 range for Annexin V-FITC and PI, respectively.

Assessment of changes of mitochondrial membrane potential $(M M P)$. MMP was measured by flow cytometry with MitoTracker Red (Invitrogen) probe, a mitochondrionselective stain that is concentrated in active mitochondria, while the reduction of MMP leads to the release of the stain. The probe was dissolved in DMSO and diluted in PBS before treatment. Cells were treated with MitoTracker for $45 \mathrm{~min}$ before trypsinization, then washed twice with PBS and analyzed by flow cytometry on a FACScan station with CellQuest software using the FL2 for MitoTracker Red staining.

Analysis of active caspase-3. Cells were collected by trypsin and the experiments were performed following the manual. Briefly, cells were fixed and permeabilized using the Cytofix/ Cytoperm $^{\mathrm{TM}}$ kit (BD Pharmingen) for $20 \mathrm{~min}$ at RT, pelleted and washed with Perm/Wash ${ }^{\mathrm{TM}}$ buffer (BD Pharmingen). Cells were then stained with FITC labeled anti-caspase-3 active form (BD Pharmingen) for $60 \mathrm{~min}$ at RT in the dark. Samples were analyzed by flow cytometry on a FACScan station with CellQuest software using the FL1 for FITC labeled caspase-3 active form.

Western blotting. Cells were rinsed in PBS and then lysed in lysis buffer containing $150 \mathrm{mM} \mathrm{NaCl}, 1 \% \mathrm{NP} 40,0.5 \%$ deoxycholic acid, $0.1 \%$ SDS, $50 \mathrm{mM}$ Tris $(\mathrm{pH} 8.0)$ and 1:25 protease inhibitor cocktail. The lysates were kept on ice for $30 \mathrm{~min}$ before centrifuging at $14000 \mathrm{rpm}$ to remove any cellular debris. For cellular fractionation, cells were washed with PBS and lysed in cytosolic lysis buffer containing $250 \mathrm{mM}$ sucrose, $70 \mathrm{mM} \mathrm{KCl}, 137 \mathrm{mM} \mathrm{NaCl}, 4.3 \mathrm{mM}$ $\mathrm{Na}_{2} \mathrm{HPO}_{4}, 1.4 \mathrm{mM} \mathrm{KH}{ }_{2} \mathrm{PO}_{4}(\mathrm{pH} 7.2), 200 \mu \mathrm{g} / \mathrm{ml}$ digitonin, $100 \mathrm{mM}$ PMSF and 1:25 protease inhibitor cocktail for $30 \mathrm{~min}$ on ice. Cells were centrifuged at $14000 \mathrm{rpm}$ for $15 \mathrm{~min}$ at $4^{\circ} \mathrm{C}$. The supernatant was saved as cytosolic protein extract. Protein concentrations of the lysates were determined by the Bradford protein assay system (Bio-Rad, Hercules, CA). Equal amounts of protein (20 $\mu \mathrm{g}$ protein each lane) were separated by SDS-PAGE, transferred to nitrocellulose membranes (Hybond C, Amersham, UK). Immunoblots were blocked with $5 \%$ skim milk in TBS/Tween-20 $(0.05 \%, \mathrm{v} / \mathrm{v})$ for $1 \mathrm{~h}$ at RT. The membrane was incubated with primary antibody overnight at $4^{\circ} \mathrm{C}$. Antibodies against cytochrome c, total AKT (t-Akt), phospho-AKT (p-Akt) and PARP were from BD Pharmingen, antibodies against XIAP and DNA-PK catalytic subunit (DNA-PKcs) were from BD transduction laboratories, and ß-actin antibody was purchased from Sigma. Following several washes with PBS containing 0.1\% Tween-20, the membrane was incubated with corresponding secondary antibody conjugated with horseradish peroxidase (Sigma), diluted in 5\% skim milk (1:5000) at RT for $1 \mathrm{~h}$. The blots were developed using an enhanced chemiluminescence Western blotting detection system (Amersham Bioscience, UK).

Statistical analysis. The data represent at least three independent experiments. Statistical comparisons were made 

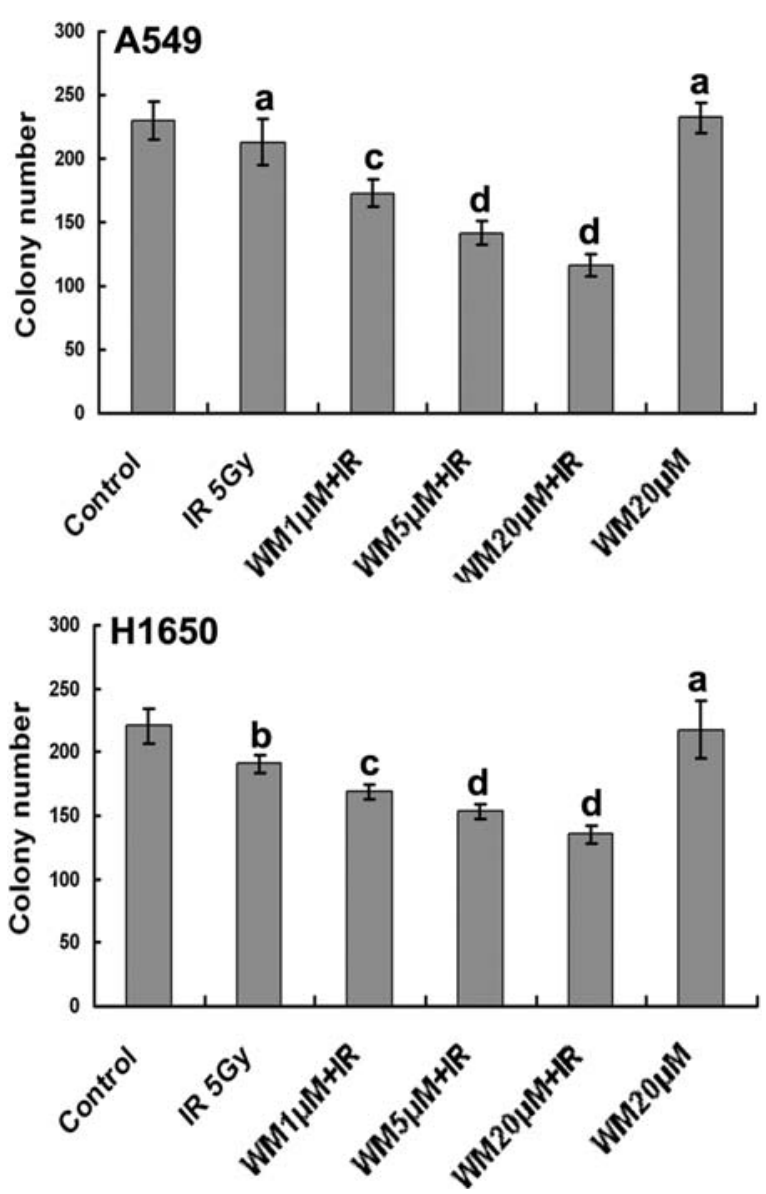

Figure 1. Pretreatment of wortmannin radiosensitizes NSCLC cells by inhibiting colony formation. NSCLC A549 and H1650 cells were incubated with different concentrations of wortmannin (WM) for $1 \mathrm{~h}$ followed by $5 \mathrm{~Gy}$ $\gamma$-irradiation. Clonogenic assay was performed 14 days after cell plating. ( ${ }^{\mathrm{a}} \mathrm{P}>0.05$ compared to control; ${ }^{\mathrm{b}} \mathrm{P}<0.05$ compared to control; ${ }^{\mathrm{c}} \mathrm{P}<0.05$ compared to IR $5 \mathrm{~Gy} ;{ }^{\mathrm{d}} \mathrm{P}<0.01$ compared to IR $5 \mathrm{~Gy}$ ).

using Student's t-test. $\mathrm{P}<0.05$ was considered to represent a stati-stically significant difference.

\section{Results}

Pretreatment of wortmannin radiosensitizes NSCLC cells by inhibiting colony formation. NSCLC A549 and H1650 cells were incubated with different concentrations of wortmannin for $1 \mathrm{~h}$ followed by $5 \mathrm{~Gy} \gamma$-irradiation. Clonogenic assay was performed 14 days after cell plating. The results (Fig. 1) showed that 5 Gy IR modestly inhibit colony formation in both cell lines. Wortmannin pretreatment significantly enhanced the inhibitory effect of 5 Gy IR in both cell lines in a dose-dependent way. The highest concentration of wortmannin $(20 \mu \mathrm{M})$ showed the best synergistic effects for increasing the radiosensitivity of NSCLC cells, while had no effect on colony formation when used alone, compared with vehicle control.

Pretreatment with wortmannin enhances IR-induced G2/M arrest and apoptosis. We then studied whether wortmannin had any effects on IR-caused cell cycle changes and apoptosis in A549 cells. We chose wortmannin $20 \mu \mathrm{M}$ to pretreat the cells according to the results of clonogenic assay. Cell cycle was detected by flow cytometry at $24 \mathrm{~h}$ after 5 Gy IR. The results (Fig. 2A and B) showed that IR caused cell cycle arrest in G2/M phase, which could be enhanced by wortmannin pretreatment, while wortmannin alone had no effect on cell cycle changes. Apoptosis was detected by Annexin V/PI staining with flow cytometry. The results (Fig. 2C) showed that cells treated with 5 Gy IR had only small amount of Annexin V positive cells. However, when cells were pretreated with wortmannin, much more apoptotic cells were observed compared to IR alone. Wortmannin itself had no effect on apoptosis compared to vehicle control. Taken together, these results indicate that wortmannin radiosensitizes NSCLC cells by enhancing G2/M cell cycle arrest and apoptosis.

Effects of wortmannin on Akt phosphorylation in NSCLC cells. Akt phosphorylation by $\mathrm{PI} 3 \mathrm{~K}$ pathway is implicated in mediating cell survival and protecting cells from apoptosis. To demonstrate that wortmannin promotes IR-induced apoptosis by repressing the PKB/Akt surviving signalling, we measured total and phosphorylated levels of Akt. The results showed that wortmannin $20 \mu \mathrm{M}$ caused a decrease of phosphorylated Akt, without affecting total Akt level. Irradiation with 5 Gy $\gamma$-ray did not change total or phosphorylated Akt level, while wortmannin pretreatment followed by IR resulted in decreased Akt phosphorylation (Fig. 3). The reduction of phosphorylated $\mathrm{PKB} / \mathrm{Akt}$ level correlated with the enhancement of IR-induced apoptosis, as indicated by Annexin V-positive cells analyzed by flow cytometry (Fig. 2C).

Wortmannin increases IR-induced loss of MMP and cytochrome c release. The loss of MMP plays a pivotal role in the initiation of apoptosis, resulting in the release of key apoptosis mediators such as cytochrome c (15), which leads to the activation of apoptosis signaling cascades. Therefore, we investigated whether wortmannin could increase the activation of mitochondrial pathway by measuring MMP changes and cytochrome $\mathrm{c}$ release in the cytoplasm. The results (Fig. 4A and B) showed that IR treatment caused a decrease of MMP compared to vehicle control, while wortmannin had no effect on MMP. However, pretreatment with wortmannin markedly increased IR-induced MMP dissipation. Consistently, cytochrome c release was significantly increased in radiated cells with wortmannin pretreatment compared to IR alone, while wortmannin itself did not cause cytochrom c release (Fig. 4C). These data suggest that wortmannin radiosensitizes NSCLC cells by enhancing the mitochondrial apoptotic pathway.

Wortmannin promotes IR-induced caspase-3 activation. Caspase-3 is a key protease of caspase family which plays an important role in apoptosis. Active caspase- 3 is the executor of apoptotic event, which is derived from the $32-\mathrm{kDa}$ protein and consists of a heterodimer of 17 and $12 \mathrm{kDa}$ subunits. We measured active caspase-3 level with flow cytometry. The results (Fig. 5A and B) showed that wortmannin $20 \mu \mathrm{M}$ alone had no effects on caspase- 3 activation, however, it enhanced the effects of IR by causing increased level of active caspase- 3 . The anti-apoptotic XIAP protein is responsible for inhibiting 
A

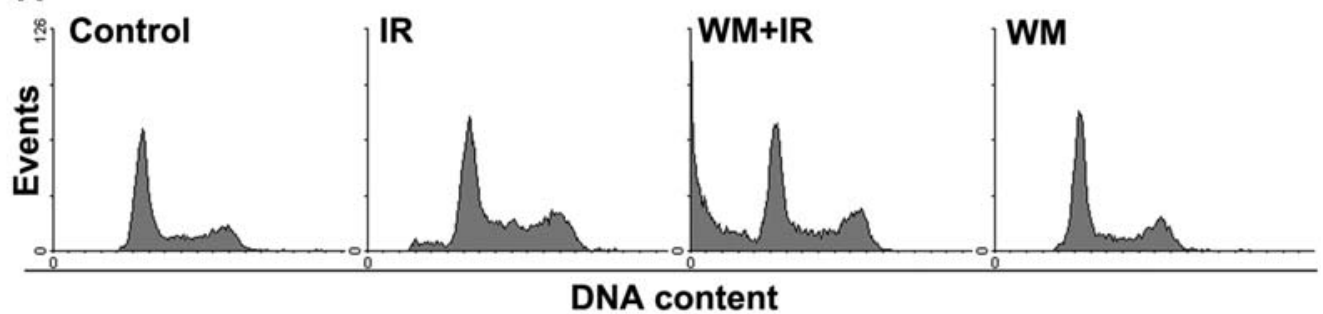

B
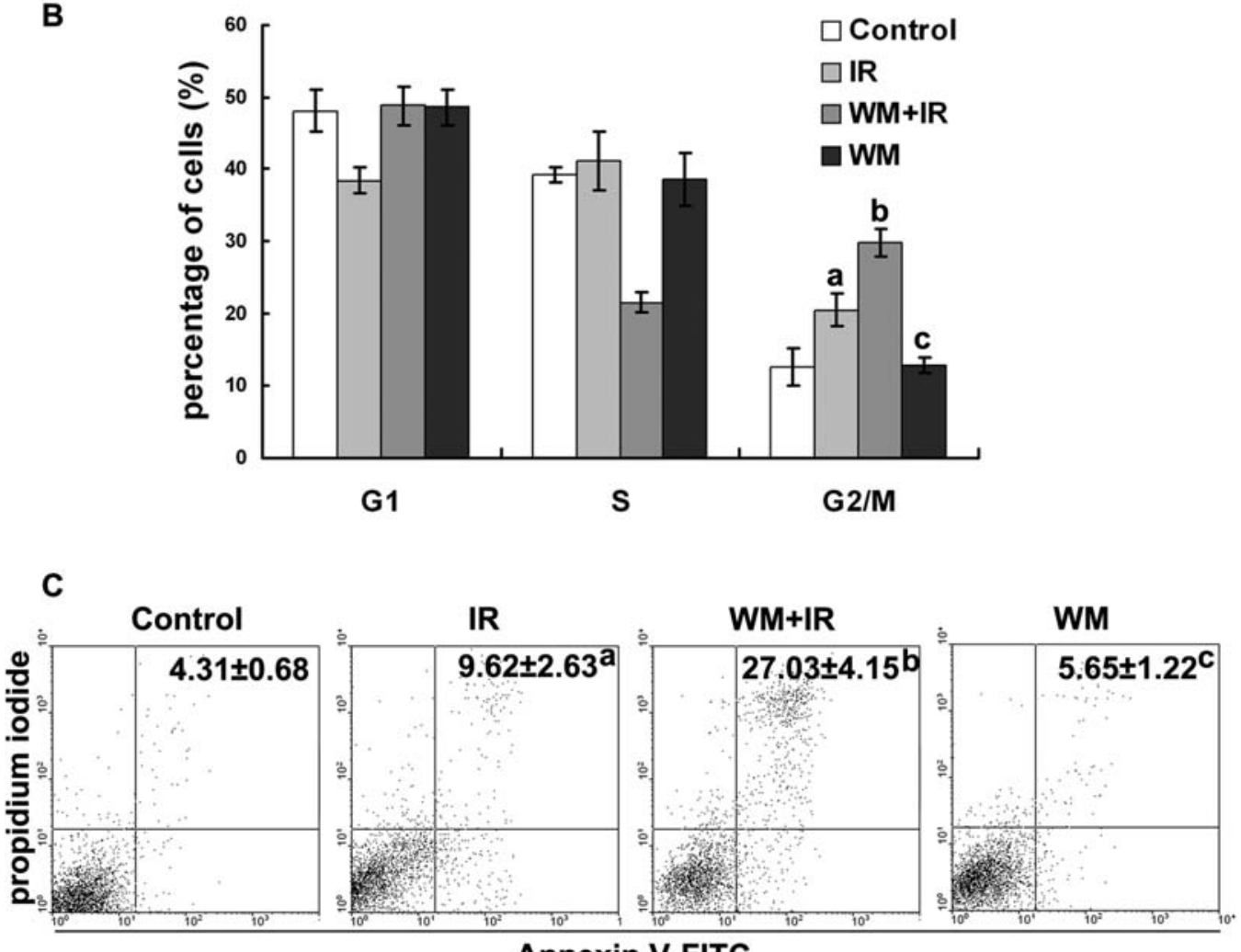

Annexin V-FITC

Figure 2. Pretreatment with wortmannin enhances IR-induced G2/M arrest and apoptosis. A549 cells were divided into 4 groups: Control, IR (5 Gy), WM+IR (wortmannin $20 \mu \mathrm{M}$ pretreat for $1 \mathrm{~h}$ follwed by IR $5 \mathrm{~Gy}$ ) and WM (wortmannin $20 \mu \mathrm{M}$ ). Cells were collected $24 \mathrm{~h}$ after different treatments. (A) Cell cycle was measured by flow cytometry and representative plots of one set of triplicate experiments are shown. (B) The percentage of G2/M cells was analyzed using WinMDI software. Data are presented as means \pm SD from 3 independent experiments and shown in bar graph. ( $\mathrm{P}<0.05$ compared to control; ${ }^{\mathrm{b}} \mathrm{P}<0.01$ compared to IR; ${ }^{c} \mathrm{P}>0.05$ compared to control). (C) Representative plots of one set of triplicate experiments of Annexin V-FITC and PI staining with percentages of Annexin V positive cells shown as means $\pm \mathrm{SD}$. ( ${ }^{\mathrm{a}} \mathrm{P}<0.05$ compared to control; ${ }^{\mathrm{b}} \mathrm{P}<0.01$ compared to IR; ${ }^{\mathrm{c}} \mathrm{P}>0.05$ compared to control).

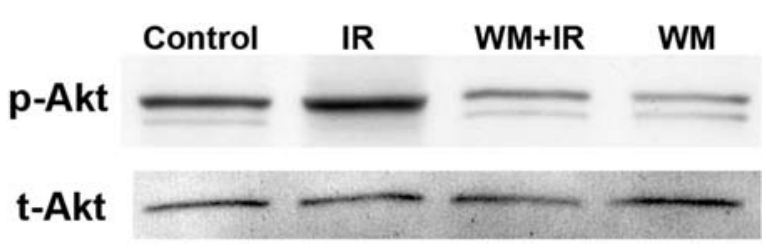

Figure 3. Wortmannin pretreatment radiosensitizes A549 cells by decreasing Akt phosphorylation. A549 cells were treated as described in Fig. 2. Western blotting with anti-total-Akt (t-Akt), phosphor-Akt (p-Akt) antibodies was performed.

apoptosis by directly binding and inhibiting caspase- 3 activation (16). Using Western blotting, we observed that pretreatment with wortmannin markedly reduced XIAP expression compared to IR alone (Fig. 5C), which were consistent with the changes of caspase-3 activity.
Since caspase-3 proteolytically cleaves its target PARP, we performed Western blot analysis to detect PARP cleavage to further verify the induction of caspase-3 activity and apoptosis. During apoptosis, PARP is cleaved from its 116 $\mathrm{kDa}$ intact form into 85 and $25 \mathrm{kDa}$ fragments by caspase- 3 . The results showed that pretreatment with wortmannin caused more cleavage of PARP in radiated cells, compared to IR alone, as indicated by a much stronger $85 \mathrm{kDa}$-band (Fig. $5 \mathrm{C})$. These results demonstrate that increased activation of caspase-3, which may be the consequence of XIAP repression, contri-butes to wortmannin-induced radiosensitivity.

Wortmannin pretreatment radiosensitizes A549 cells through down-regulation of DNA-PKcs and inhibition of $D S B$ s rejoining. In cancer cells, efficient DNA repair activity is considered to be an important reason for radiotherapeutic resistance (17). WM binds to the kinase domain of DNA- 


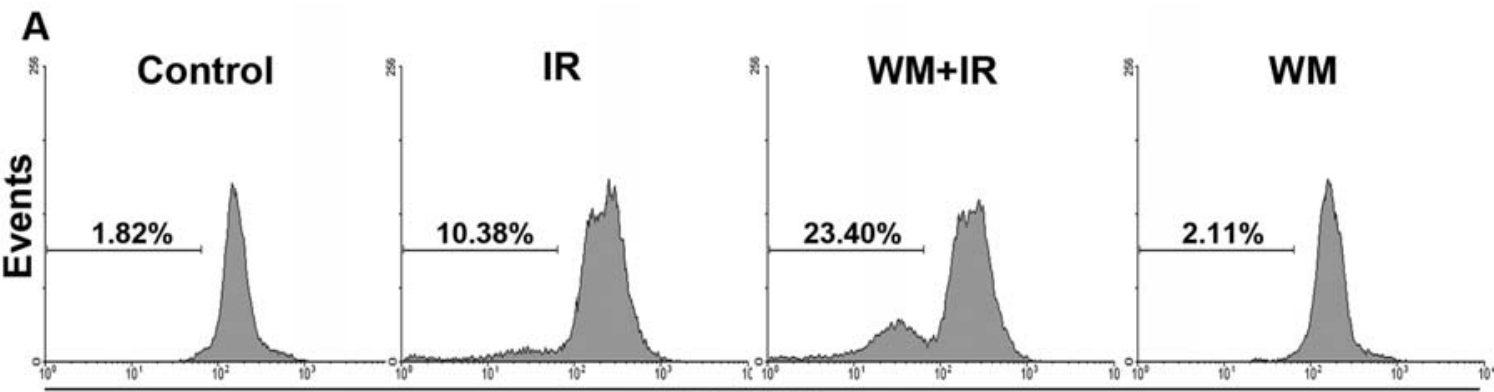

FL2-MMP

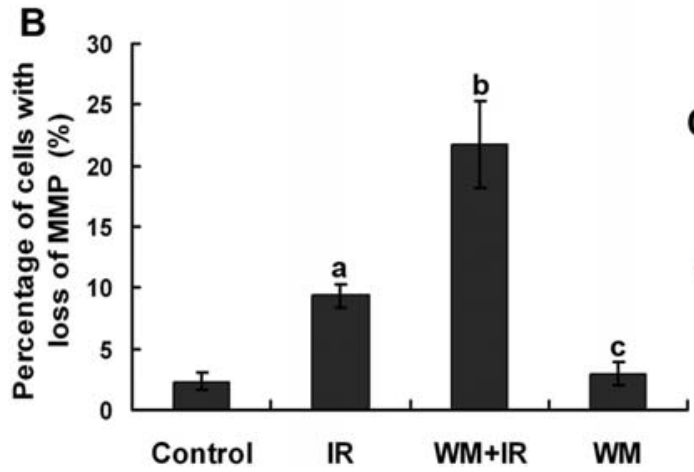

C

\section{control IR WM+IR WM}

cytochrome c

Actin

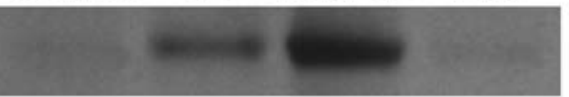

Figure 4. Wortmannin increases IR-induced MMP dissipation and cytochrome c release. A549 cells were treated as described in Fig. 2. (A) Representative plots of one set of triplicate experiments measuring MMP changes by flow cytometry. (B) MMP changes were analyzed using WinMDI software. Data are presented as means $\pm \mathrm{SD}$ from 3 independent experiments and shown in bar graph. $\left({ }^{\mathrm{a}} \mathrm{P}<0.01\right.$ compared to vehicle control; ${ }^{\mathrm{b}} \mathrm{P}<0.01$ compared to IR $5 \mathrm{~Gy}$; 'P $>0.05$ compared to control). (C) Cytosolic protein was extracted and $20 \mu \mathrm{g}$ protein was loaded on each lane. Western blotting with anti-cytochrome $\mathrm{c}$ and anti-Actin antibodies was performed.

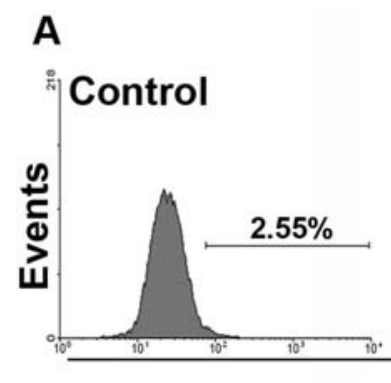

B

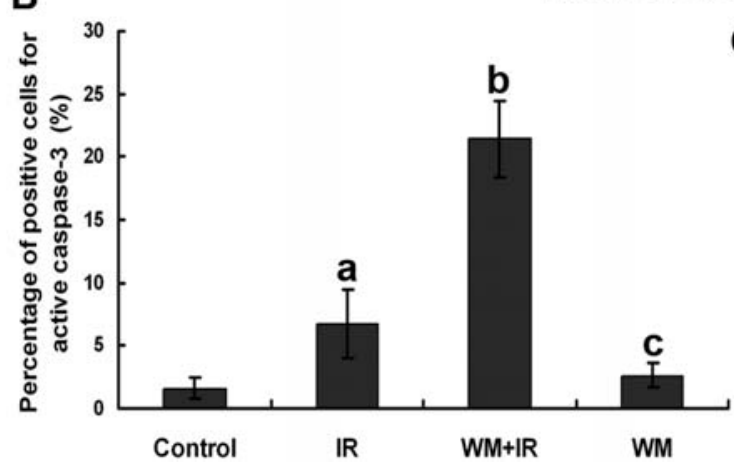

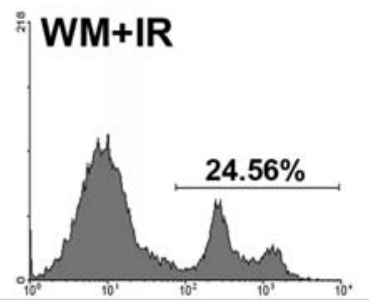

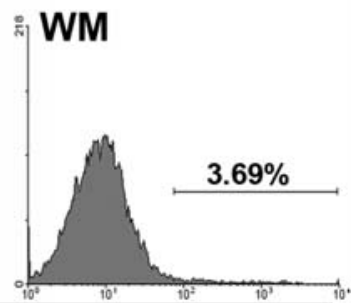

C

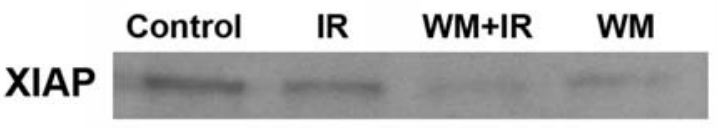

PARP

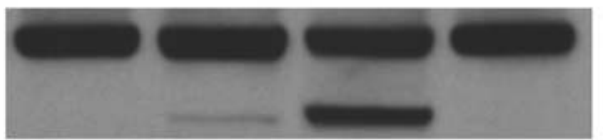

Actin

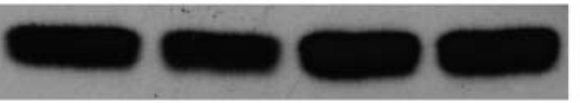

Figure 5. Wortmannin promotes IR-induced caspase-3 activation. A549 cells were treated as described in Fig. 2. (A) Representative plots of one set of triplicate experiments measuring active caspase-3 by flow cytometry. (B) The percentage of active caspase-3 positive cells was analyzed using WinMDI software. Data are presented as means $\pm \mathrm{SD}$ from 3 independent experiments and shown in bar graph. $\left({ }^{a} \mathrm{P}<0.05\right.$ compared to vehicle control; ${ }^{b} \mathrm{P}<0.01$ compared to IR $5 \mathrm{~Gy}$; ${ }^{\mathrm{P}}>0.05$ compared to control). (C) Western blotting with anti-PARP, anti-XIAP and anti-Actin antibodies was performed.

PKcs and inhibits DNA-PK function in vitro and in vivo (18). Its sensitizing effect most likely results from the inhibition of DSBs repair, specifically non-homologous end joining (NHEJ) (19), which is known to be one of the major DNA DSB repair pathways in mammalian cells. We analyzed the effects of wortmannin pretreatment in radiated cells by Western blotting, on the expression of DNA-PKcs and $\gamma$-H2AX, a marker of DSBs. As shown in Fig. 6, DNA-PKcs was slightly 


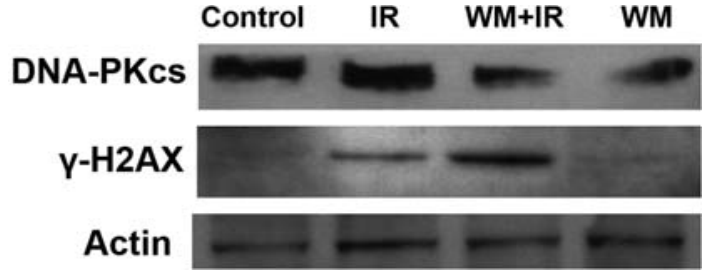

Figure 6. Wortmannin pretreatment down-regulated expression of DNAPKcs and inhibited DSBs rejoining. A549 cells were treated as described above and collected at $24 \mathrm{~h}$ after IR. Western blotting with anti-DNA-PKcs, $\gamma-\mathrm{H} 2 \mathrm{AX}$ and Actin antibodies was performed.

increased at $24 \mathrm{~h}$ after IR, suggesting the activation of DNA repair system after IR. Wortmannin alone or with IR downregulated the expression of DNA-PKcs, leading to an enhanced expression of $\gamma-\mathrm{H} 2 \mathrm{AX}$ at $24 \mathrm{~h}$ after IR. These results suggest that repressed DNA repair may be a mechanism by which wortmannin induces radiosensitivity in NSCLC cells.

\section{Discussion}

Radiotherapy with $\gamma$-irradiation is the major therapeutic option in cancer treatment. However, many tumors have shown radioresistance which greatly limits the effect of radiotherapy. Cancer cells tend to be resistant to radiotherapy due to defects in apoptosis, overexpression of genes related to cell survival (4), and enhanced DNA repair activity. It has been demonstrated that NSCLC cells have up-regulated level of PI3K/Akt pathway (20) which is implicated in radioresistance. In the current study, we observed that inhibition of PI3K signaling by wortmannin radiosensitized NSCLC cells by significantly decreasing the colony formation ability in these cells. The enhanced growth inhibition was due to G2/M cell cycle arrest and apoptosis, which was accompanied by inhibition of Akt phosphorylation.

Akt activation by phosphorylation has been demonstrated to deliver anti-apoptotic survival signals through phosphorylation of proapoptotic proteins such as BAD (21) and Bax (22). Akt phosphorylates Bax at Ser ${ }^{184}$, leading to Bax inactivation (23). Bax activation includes Bax oligomerization and subsequent translocation. Bax oligomerization has also been proposed to facilitate the de novo pore formation or the opening of the existing channels in the outer mitochondrial membrane, allowing the release of cytochrome $\mathrm{c}$ in the cytoplasm (24). In the present study, we showed that wortmannin enhanced IR-induced dissipation of MMP. Loss of MMP is an early sign of mitochondrial injury, which induces the permeabilization of mitochondrial membrane that facilitates the release of critical proapoptotic proteins from the mitochondria into the cytoplasm, including cytochrome c, leading to the activation of caspase- 9 and downstream cleavage of caspase-3. As expected, increased cytochrome c release in the cytoplasm was observed with wortmannin pretreatment. Subsequently, caspase-3 activation was greatly increased as indicated by the level of the active form of caspase-3, which is the executor of apoptosis. XIAP belongs to the inhibitor of apoptosis proteins (IAPs) family. IAPs are overexpressed in many cancers and implicated in tumor pathogenesis, growth, and resistance to chemo- or radiotherapy. XIAP is the most potent caspase inhibitor in this family (25). Uchida et al (26) have reported that PI $3 \mathrm{~K}$ inhibitors wortmannin and LY294002 down-regulate XIAP expression, which is one of the mecha-nisms mediating the enhanced susceptibility to TRAIL-induced apoptosis in oral squamous carcinoma cells. Here, we also showed that wortmannin down-regulated XIAP expression in NSCLC A549 cells, leading to increased caspase- 3 activation and, as a consequence, wortmannin dramatically enhanced IR-induced apoptosis.

IR causes DNA double-strand breaks (DSBs), one of the most fatal forms of DNA damage. There are two ways to repair DNA DSBs in eukaryotic cells: homologous recombination (HR) and non-homologous end-joining (NHEJ) (27). Ativation of DNA repair activity of cancer cells after DNA damage caused by IR might be one reason for radioresistance (28). The NHEJ pathway of DNA DSBs is initiated by the DNA-PK complex, which consists of DNA-PK catalytic subunit (DNA-PKcs), and the Ku DNA-binding subunits, $\mathrm{Ku} 70$ and Ku80 (29). It has been shown that inhibition or deletion of DNA-PKcs renders cells highly sensitive to DSBs induced by IR and DNA damaging agents (30). DNAPKcs is a member of a subfamily of proteins containing the phosphatidylinositol (PI)-3 kinase domain, which could be inhibited by wortmannin. Ortiz et al (11) have reported that WM-dependent radiosensitization in RT112 radioresistant bladder tumor cells is a direct consequence of the inhibition of DNA-PK, resulting in the inhibition of DSB repair, suggesting that the expression level of DNA-PKcs in human tumor cells may be a good predictor for the success of DNAPKcs inhibitors when used as radiosensitizers. In vivo assays revealed that wortmannin, in combination with radiation therapy, may have potential benefits in cancer treatment for $\mathrm{C} 3 \mathrm{H} / \mathrm{HeJ}$ hepatocarcinoma (13). Sak et al (14) reported that the inhibition of DNA-dependent protein kinase activity by wortmannin led to marked inhibition of the rejoining of DNA double strand breaks (DSBs). We confirmed that in NSCLC A549 cells, wortmannin repressed DNA-PKcs, as a consequence, DNA DSBs repair activity was inhibited, as indicated by an enhanced expression of $\gamma-\mathrm{H} 2 \mathrm{AX} 24 \mathrm{~h}$ after IR. Yan et al (31) observed that vanillin derivative bromovanin induced apoptosis in Jurkat cells via mechanisms including cleavage of DNA-PKcs and subsequent increase of DNA DSBs and Akt inactivation. DNA-PKcs has been suggested to be a target for caspase-3 $(31,32)$. We postulate based on the current results that the inactivation of DNA-PKcs might be through the direct inhibition of kinase activity by wortmannin and the degradation of DNA-PKcs by increased caspase-3 activity.

Taken together, the present study demonstrates that inhibition of PI3K/Akt cell survival signaling pathway and DNA repair protein DNA-PKcs may contribute to wortmannininduced radiosensitivity in NSCLC cells. Our results provide further support for a promising strategy combining PI3K inhibitors and $\gamma$-irradiation for clinical treatment of human NSCLC.

\section{References}

1. Palayoor ST, Macklis RM, Bump EA and Coleman CN: Modulation of radiation-induced apoptosis and G2/M block in murine T-lymphoma cells. Radiat Res 141: 235-243, 1995. 
2. Ning S and Knox SJ: G2/M-phase arrest and death by apoptosis of HL60 cells irradiated with exponentially decreasing lowdose-rate gamma radiation. Radiat Res 151: 659-669, 1999.

3. Zhivotovsky B and Orrenius S: Defects in the apoptotic machinery of cancer cells: role in drug resistance. Semin Cancer Biol 13: 125-134, 2003.

4. Itoh N, Semba S, Ito M, Takeda H, Kawata S and Yamakawa M: Phosphorylation of Akt/PKB is required for suppression of cancer cell apoptosis and tumor progression in human colorectal carcinoma. Cancer 94: 3127-3134, 2002.

5. Mungamuri SK, Yang X, Thor AD and Somasundaram K: Survival signaling by Notch1: mammalian target of rapamycin (mTOR)-dependent inhibition of p53. Cancer Res 66: 4715-4724, 2006.

6. Liu Z and Roberts TM: Human tumor mutants in the p110 $\alpha$ subunit of PI3K. Cell Cycle 5: 675-677, 2006.

7. Hersey $\mathrm{P}$ and Zhang XD: Overcoming resistance of cancer cells to apoptosis. J Cell Physiol 196: 9-18, 2003.

8. Ng SSW, Tsao MS, Chow S and Hedley DW: Inhibition of phosphatidylinositide 3-kinase enhances gemcitabine-induced apoptosis in human pancreatic cancer cells. Cancer Res 60: 5451-5455, 2000.

9. Kim CH, Park SJ and Lee SH: A targeted inhibition of DNAdependent protein kinase sensitizes breast cancer cells following ionizing radiation. J Pharmacol Exp Ther 303: 753-759, 2002.

10. Powis G, Bonjouklian R, Berggren MM, et al: Wortmannin, a potent and selective inhibitor of phosphatidylinositol-3-kinase. Cancer Res 54: 2419-2423, 1994.

11. Ortiz T, Burguillos MA, López-Lluch G, et al: Enhanced induction of apoptosis in a radio-resistant bladder tumor cell line by combined treatments with X-rays and wortmannin. Radiat Environ Biophys 47: 445-452, 2008.

12. Soderlund K, Perez-Tenorio G and Stal O: Activation of the phosphatidylinositol 3-kinase/Akt pathway prevents radiationinduced apoptosis in breast cancer cells. Int J Oncol 26: 25-32, 2005.

13. Kim W, Seong J, An JH and Oh HJ: Enhancement of tumor radioresponse by wortmannin in $\mathrm{C} 3 \mathrm{H} / \mathrm{HeJ}$ hepatocarcinoma. J Radiat Res 48: 187-195, 2007.

14. Sak A, Stuschke M, Wurm R, et al: Selective inactivation of DNA-dependent protein kinase with antisense oligodeoxynucleotides: consequences for the rejoining of radiation-induced DNA double-strand breaks and radiosensitivity of human cancer cell lines. Cancer Res 62: 6621-6624, 2002.

15. Reed JC: Cytochrome c: can't live with it-can't live without it. Cell 91: 559-562, 1999.

16. Bratton SB, Walker G, Srinivasula SM, et al: Recruitment, activation and retention of caspases- 9 and -3 by Apaf- 1 apoptosome and associated XIAP complexes. EMBO J 20: 998-1009, 2001.

17. Madhusudan S and Middleton MR: The emerging role of DNA repair proteins as predictive, prognostic and therapeutic targets in cancer. Cancer Treat Rev 31: 603-617, 2005.
18. Izzard RA, Jackson SP and Smith GC: Competitive and noncompetitive inhibition of the DNA-dependent protein kinase. Cancer Res 59: 2581-2586, 1999.

19. DiBiase SJ, Zeng ZC, Chen R, Hyslop T, Curran WJ Jr and Iliakis G: DNA-dependent protein kinase stimulates an independently active, non-homologous, end-joining apparatus. Cancer Res 60: 1245-1253, 2000.

20. Brambilla E and Gazdar A: Pathogenesis of lung cancer signalling pathways: roadmap for therapies. Eur Respir J 33: 1485-1497, 2009

21. Datta SR, Dudek H, Tao X, et al: Akt phosphorylation of BAD couples survival signals to the cell-intrinsic death machinery. Cell 91: 231-241, 1997.

22. Havasi A, Li ZJ, Wang ZY, et al: Hsp27 inhibits Bax activation and apoptosis via a PI3 kinase-dependent mechanism. J Biol Chem 283: 12305-12313, 2008.

23. Gardai SJ, Hildeman DA, Frankel SK, et al: Phosphorylation of Bax Ser184 by Akt regulates its activity and apoptosis in neutrophils. J Biol Chem 279: 21085-21095, 2004.

24. De Giorgi F, Lartigue L, Bauer MK, et al: The permeability transition pore signals apoptosis by directing Bax translocation and multimerization. FASEB J 16: 607-609, 2002.

25. Eckelman BP, Salvesen GS and Scott FL: Human inhibitor of apoptosis proteins: why XIAP is the black sheep of the family. EMBO Rep 7: 988-994, 2006.

26. Uchida M, IWASE M, Takaoka S, et al: Enhanced susceptibility to tumor necrosis factor-related apoptosis-inducing ligand-mediated apoptosis in oral squamous cell carcinoma cells treated with phosphatidylinositol 3-kinase inhibitors. Int J Oncol 30: 1163-1171, 2007

27. Liang F, Han M, Romanienko PJ and Jasin M: Homologydirected repair is a major double-strand break repair pathway in mammalian cells. Proc Natl Acad Sci USA 95: 5172-5177, 1998.

28. Friesen C, Glatting G, Koop B, et al: Breaking chemoresistance and radioresistance with [213Bi] anti-CD45 antibodies in leukemia cells. Cancer Res 67: 1950-1958, 2007.

29. Khanna KK and Jackson SP: DNA double-strand breaks: signaling, repair and the cancer connection. Nat Genet 27: 247-254, 2001.

30. Smider V, Rathmell WK, Lieber MR and Chu G: Restoration of $\mathrm{X}$-ray resistance and $\mathrm{V}(\mathrm{D}) \mathrm{J}$ recombination in mutant cells by $\mathrm{Ku}$ cDNA. Science 266: 288-291, 1994.

31. Yan YQ, Xu QZ, Wang L, Sui JL, Bai B and Zhou PK: Vanillin derivative 6-bromine-5-hydroxy-4-methoxybenzaldehydeelicited apoptosis and G2/M arrest of Jurkat cells proceeds concurrently with DNA-PKcs cleavage and Akt inactivation. Int J Oncol 29: 1167-1172, 2006.

32. Han Z, Malik N, Carter T, Reeves WH, Wyche JH and Hendrickson EA: DNA-dependent protein kinase is a target for a CPP32-like apoptotic protease. J Biol Chem 271: 25035-25040, 1996. 